\title{
A Novel Sequential Docking Technique: Use of Femtosecond Arcuate Keratotomy and Femtosecond Assisted Cataract Surgery Using a Pupil Expansion Ring on a Patient with Intraoperative Floppy Iris Syndrome
}

This article was published in the following Dove Press journal: International Medical Case Reports Journal

\author{
Hung-Yuan Lin $\mathbb{D}^{1-3}$ \\ Ting-Yu Lin $\mathbb{1}^{4}$ \\ Ya-Jung Chuang ${ }^{5}$ \\ Li-Ju Lai ${ }^{6}$ \\ Pi-Jung Lin $\mathbb{D}^{7}$
}

'Department ofOpthalmology, Universal Eye Center, Zhong-Li, Taiwan, Republicof China; ${ }^{2}$ Department of Optometry,

Central Taiwan University of Science and Technology, Taichung City, Taiwan, Republicof China; ${ }^{3}$ Department of Ophthalmology, Shanghai Ruidong Hospital, Shanghai, People's Republic ofChina; ${ }^{4}$ Department of Chemistry, Barnard College, Columbia University New York, New York, NY, USA; ${ }^{5}$ Department of Ophthalmology, Universal Eye Center, Long-Tan, Taiwan, Republicof China; ${ }^{6}$ Department of Ophthalmology, Universal Eye Center, Chia-Yi, Taiwan, Republic ofChina; ${ }^{7}$ Department of Ophthalmology, Universal Eye Center, Taipei, Taiwan, Republic ofChina
Correspondence: Ya-Jung Chuang Tel + 886-983308370

Email rannyposh@gmail.com
Purpose: The purpose of this study was to evaluate the efficacy of a novel double-docking technique, incorporating the use of femtosecond laser arcuate keratotomy (FSAK) in correcting lowdegree astigmatism and Malyugin ring, in a patient with intraoperative floppy iris syndrome (IFIS). Methods: A case report of a 72-year-old man with grade 4 cataract, low-degree astigmatism $(<2 \mathrm{D}$ ), and IFIS (pupil size $<4 \mathrm{~mm}$, intraoperatively) is presented. The patient underwent cataract surgery using a femtosecond laser to treat low-degree astigmatism because the patient requested for the use of a multifocal intraocular lens (IOL). The first docking was performed to complete arcuate keratotomy, produce the mainparacentesis incisions, and create clear corneal incisions. Insertion of the Malyugin ring was performed after the first docking, whereas the second one was executed to complete continuous curvilinear capsulotomy and lens fragmentation. The patient's uncorrected visual acuity (UCVA) was measured pre- and post-operatively. The complications were evaluated post-operatively and 3 months later during the follow-up visit.

Results: The patient's UCVA for distance improved from 0.3 (6/12 Snellen equivalent) to 0 (6/6 Snellen equivalent) $\log$ MAR post-operatively. During the follow-up visit, the patient's uncorrected near visual acuity was at $\mathrm{J} 2$. His corneal astigmatism changed from -1.0 Diopter @ $177^{\circ}$ pre-operative to $-0.12 \mathrm{D} @ 173^{\circ}$ post-operative. No other intraoperative or postoperative complications were observed.

Conclusion: The double-docking technique, with the use of FSAK, and Malyugin ring produced successful surgical outcomes for the patient. The benefits of this technique allow surgeons to avoid changing the shape of the patient's cornea from the injection of the viscoelastic device into the anterior chamber, which could lower the femtosecond laser's precision and docking location.

Keywords: femtosecond laser arcuate keratotomy, Malyugin ring, low-degree, astigmatism, intraoperative floppy iris syndrome

\section{Introduction}

Precise management of astigmatism is critical for achieving excellent postoperative uncorrected visual acuity (UCVA) outcomes. Degradation of visual quality occurs when residual refractive astigmatism $\geq 0.5$ Diopter (D) is present in eyes receiving multifocal lens implants. ${ }^{1}$ Successful use of the femtosecond laser arcuate 
keratotomy (FSAK) to treat low-to-moderate corneal astigmatism has been previously reported. ${ }^{2}$ However, to the best of our knowledge, no case report has discussed the use of FSAK for the correction of astigmatism combined with a Malyugin pupil expansion ring on a patient with poorly dilating pupils (intraoperative floppy iris syndrome or IFIS).

In patients with poorly dilating pupils, performing cataract surgeries is difficult owing to the potential increase in the intraoperative complications. ${ }^{3,4}$ Although iris hooks ${ }^{5}$ and pharmacological ${ }^{6}$ approaches can be attempted to expand the patient's pupil, a more effective solution would be to use a Malyugin ring. ${ }^{7,8}$ The device stabilizes the expansion of the patient's pupil throughout the surgical duration and has no sharp ends, thereby preventing damage to the intraocular tissues. ${ }^{9}$

The femtosecond laser-assisted cataract surgery (FLACS) automates many of the steps required in manual cataract surgeries. ${ }^{10}$ The procedure allows the surgeons to perform accurate correction of corneal astigmatism ${ }^{11}$ precise clear corneal incisions $(\mathrm{CCI}),{ }^{12}$ reproducible circular continuous curvilinear capsulotomy (CCC), and endothelium protection during lens fragmentation. ${ }^{13}$ However, the femtosecond laser's advantages for CCC and lens fragmentation are not accessible to patients with IFIS as it is unable to reach the patient's lens through the poorly dilated pupils. When a Malyugin ring is inserted, the injection of the viscoelastic device changes the shape of the cornea and thus minimizes the effect of FSAK if performed after the viscoelastic insertion. Performing the FSAK as the very first step ensures the accuracy of astigmatism treatment, and further steps of the FLACS can be applied after the viscoelastic and Malyugin ring insertions. In some operating theater settings, the two steps of FLACS may require a patient transfer from the laser bed to the operating room.

The new femtosecond laser model, Femto LDV Z8 (Ziemer; Port, Switzerland), is mobile and can hence be placed next to the operating microscope and the phacoemulsification device; the femtosecond laser procedures can be performed on the same surgical table as the cataract surgeries without the need for patient transfer. ${ }^{14}$ The device is also capable of performing the FSAK, which offers superior incisional accuracy and reproducibility, and its unique low pulse energy ensures minimal effects on the collateral tissues. This technique obviates the insertion of a toric lens and can thus be considered a safer and more economical means for the correction of low-tomoderate corneal astigmatism. ${ }^{15}$
The proximity of the Femto LDV Z8 to the patient's bed allowed us to employ a double-docking technique and conduct the procedure of FSAK and CCI separately from CCC and lens fragmentation. This two-step procedure, without any patient transfer, maximizes the benefits of FLACS.

\section{Case Report}

A 72-year-old Asia man with grade 4 cataract (Lens Opacities Classification System III used at the slit lamp) was scheduled to have right eye cataract surgery under local anesthetics (Alcaine; Alcon, Fort Worth, TX). A multifocal IOL was used. Approval was obtained from the Institutional Review Board of Antai TianSheng Memorial Hospital. The patient was on medications to control benign prostate hypertrophy (tamsulosin), blood pressure (betaxolol, in addition to losartan and hydrochlorothiazide), blood sugar (sitagliptin and glimepiride), insomnia (estazolam), and arrhythmia (propafenone). The conventional pre-operative approach to expand the patient's pupil was undertaken. Three days prior to the surgery, $0.5 \%$ atropine was administered to the eye in which the surgery was planned, and tamsulosin was discontinued. The patient is allergic to non-steroidal antiinflammatory drugs (NSAIDs); hence, we did not administer NSAID eye drops before the FLACS.

\section{Pre-Operative Assessments}

Under the slit lamp examination, the cornea was clear, the anterior chamber was deep and quiet, and a normal optic nerve and retina were observed. The other examinations, including OCT and topography, indicated that the patient was a suitable candidate for cataract surgery with no obvious retinal or corneal disease. The patient had an anterior chamber depth of $2.33 \mathrm{~mm}$ and an eye axial length of $23.74 \mathrm{~mm}$. The data were measured with an AL-Scan Optical Biometer (Nidek, Japan).

The pre-operative corneal astigmatism was -1.0 Diopter (D) @ $177^{\circ}$, as measured with a Topcon KR-8800 auto kerato-refractometer. Mydrin-p (Santen; Japan) was used to dilate the patient's pupil pre-operatively; however, it remained at $<4 \mathrm{~mm}$, and IFIS was highly suspected.

\section{Surgical Technique}

A Verion image guiding system (Alcon, Fort Worth, TX) was used to register the patient's iris fingerprint pre-operatively to account for the eye's cyclorotation. A pre-operative image of the patient's eye was captured while the patient was seated and superimposed onto the operating microscope's surgical field. Using a 27 -gage needle with ink, the $0-180^{\circ}$ horizontal axis on the corneal limbus was marked, and it was guided by the Verion image guiding system (Figure 1). 


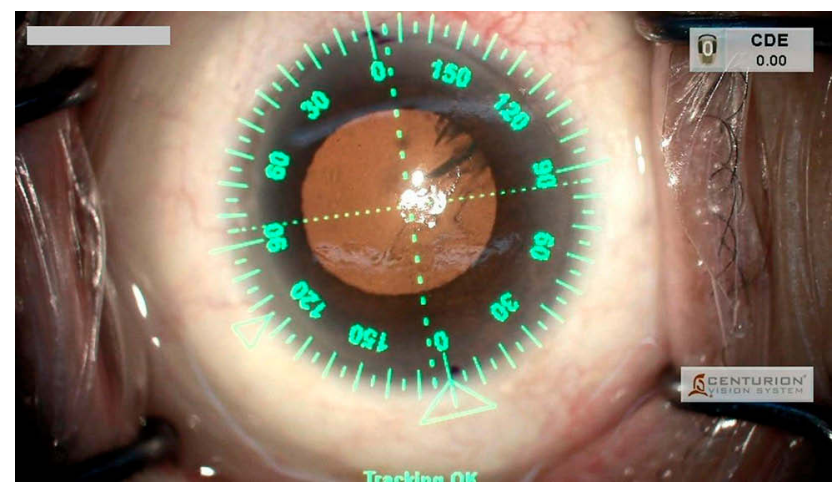

Figure I Using a 27 -gauge needle with ink, the $0^{\circ}-180^{\circ}$ horizontal axis on the corneal limbus was marked, guided by the Verion image guiding system. Cumulative dissipated energy (CDE) was set at 0.00 when the figure was captured.

The first docking (Figure 2) was performed by using the above reference ink marks to compensate for the cyclorotation. A single arcuate incision with an optical zone diameter of $8.5 \mathrm{~mm}$ and an arc angle of $35^{\circ}$ was created at $1^{\circ}$ step axis position, $90^{\circ}$ side cut angle, $0 \%$ anterior incision depth, $80 \%$ posterior depth, and $95 \%$ laser power. The femtosecond laser was also set to create a $2.3 \mathrm{~mm}$ wide main incision at the $180^{\circ}$ position, with a $40^{\circ}$ entrance angle and $-50^{\circ}$ bend angle. A $1 \mathrm{~mm}$ wide paracentesis incision was created at the $120^{\circ}$ position, with a $5^{\circ}$ entrance angle and $0^{\circ}$ bend angle. The laser power used for CCI was set at 115\% (settings: Table 1).

After opening the main incisions by using a blunt tip, the anterior chamber was inflated with a viscoelastic device (Protectalon; VSY Biotechnology, Amsterdam, The Netherlands). Subsequently, a Malyugin ring, which is a pupil-expanding device, was injected via the main incision to the anterior chamber and placed on the patient's iris (Figure 3). Hydro sealing of the main incision was performed without irrigating or aspirating the viscoelastic device out of the anterior chamber. The second docking of the femtosecond laser handpiece to the eye (Figure 4) was accomplished. Later, a circular capsulotomy with limbus centration was completed. Lens fragmentation with a diameter of $5.8 \mathrm{~mm}$ was achieved using a laser power of $125 \%$, and four fragments were produced (for details of the settings, please refer to Table 2).

Standard microincision cataract removal, hydrodissection, phacoemulsification, and irrigation/aspiration of the cortex were then performed with the phacoemulsification vision system (Centurion; Alcon). The anterior chamber and capsular bag were inflated with a viscoelastic device (Provisc; Alcon, Fort Worth, TX). An Oculentis Comfort LS313 MF15 with $\mathrm{a}+21.5 \mathrm{D}$ was injected into the patient's capsular bag. The trailing eyelet of the Malyugin ring was disengaged from the iris, and the manipulator was used to hook onto the trailing eyelet and into the injector plate (Figure 5). The removal of the viscoelastic device was performed, which was followed by irrigation and aspiration (Figure 6). All wounds were hydrosealed. (Video 1) Antibiotic and steroid drops (Pred Forte and Cravit; Allergan, Dublin, Ireland; and Santen, Japan) were administered four times a day after the surgery for 2 weeks.

\section{Outcomes and Follow-Up}

The follow-up of the patient's surgical eye was conducted 3 months post-operatively. The UCVA for distance improved from 0.3 (6/12 Snellen equivalent) to 0 (6/6 Snellen equivalent) $\log$ MAR. In addition, the patient's uncorrected near

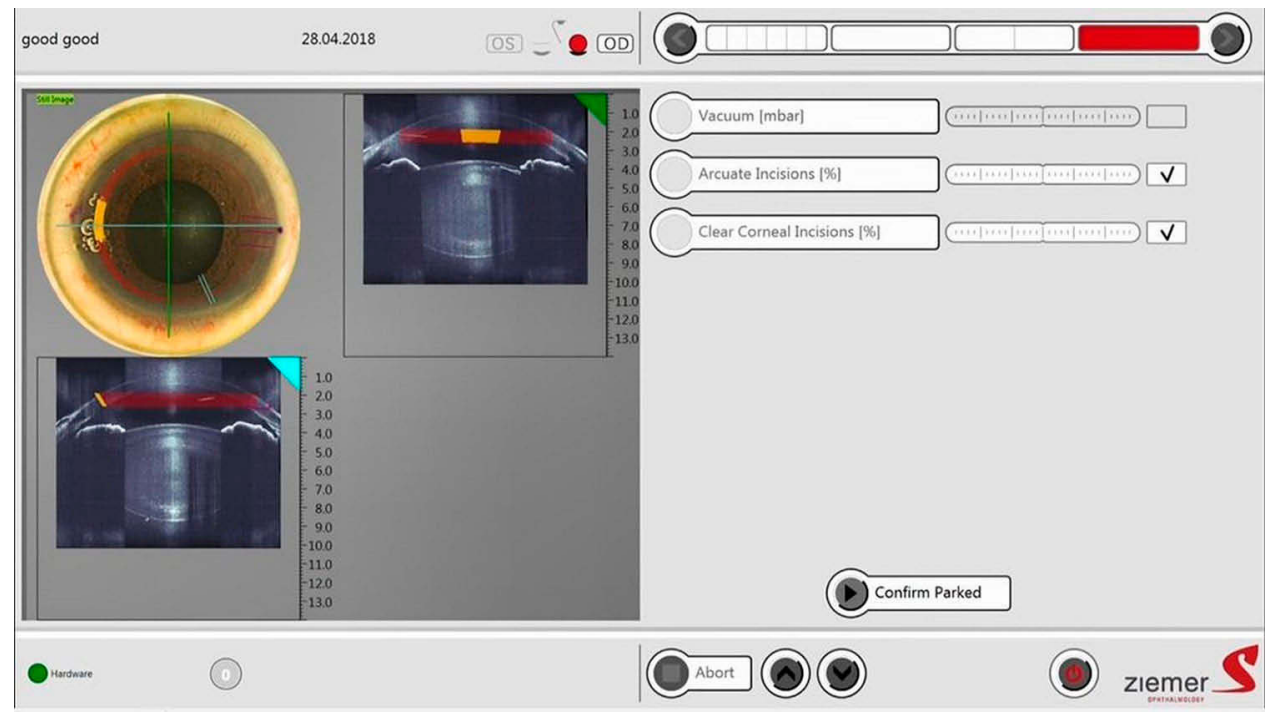

Figure 2 First docking image from Z8. 
Table I Settings of the First Docking Oculus Dextrus (O)D

\begin{tabular}{|c|c|c|c|c|}
\hline \multicolumn{5}{|c|}{ First Docking } \\
\hline OD & & Arc & & $\mathrm{CCl}$ \\
\hline & $\begin{array}{l}\text { Optical Zone } \\
\text { Diameter (mm) } \\
\text { Arc Angle }\left({ }^{\circ}\right) \\
\text { Position }\left({ }^{\circ}\right) \\
\text { Side Cut Angle }\left({ }^{\circ}\right) \\
\text { Anterior Incision } \\
\text { Depth (\%) } \\
\text { Posterior Incision } \\
\text { Depth (\%) } \\
\text { Power (\%) }\end{array}$ & $\begin{array}{l}90 \\
0\end{array}$ & $\begin{array}{l}\text { Main Incision Position }\left({ }^{\circ}\right) \\
\text { Main Incision Width (mm) } \\
\text { Main Incision Entrance } \\
\text { Angle }\left(^{\circ}\right) \\
\text { Main Incision Bend Angle }\left({ }^{\circ}\right) \\
\text { Paracentesis Incision } \\
\text { Position }\left(^{\circ}\right) \\
\text { Paracentesis Incision } \\
\text { Width (mm) } \\
\text { Laser Power (\%) } \\
\text { Main Incision Bend Angle }\left({ }^{\circ}\right) \\
\text { Paracentesis Incision } \\
\text { Entrance Angle }\left(^{\circ}\right)\end{array}$ & $\begin{array}{l}-50 \\
120 \\
1 \\
115 \\
0 \\
5\end{array}$ \\
\hline
\end{tabular}

visual acuity was at $\mathrm{J} 2$. His corneal astigmatism changed from $-1.0 \mathrm{D} @ 177^{\circ}$ pre-operative to $-0.12 \mathrm{D} @ 173^{\circ}$ postoperative. No intraoperative or post-operative complications were observed.

\section{Discussion and Conclusion}

This IFIS case highlights the successful combinatorial use of the novel double-docking technique, femtosecond laser, and the Malyugin ring to allow patients with not well dilated pupils to receive the benefits of the femtosecond laser for correcting low-degree astigmatism.

More importantly, as the patient's astigmatism was lower than 2D, FSAK is an effective and economical way of correcting the problem. ${ }^{2,16}$ Moreover, $9-30 \%$ of toric Intraocular lens (IOLs) have been reported to exhibit rotation by 5 or more degrees in the first 12 post-operative months. The toric correction from IOL implantation could be reduced by the

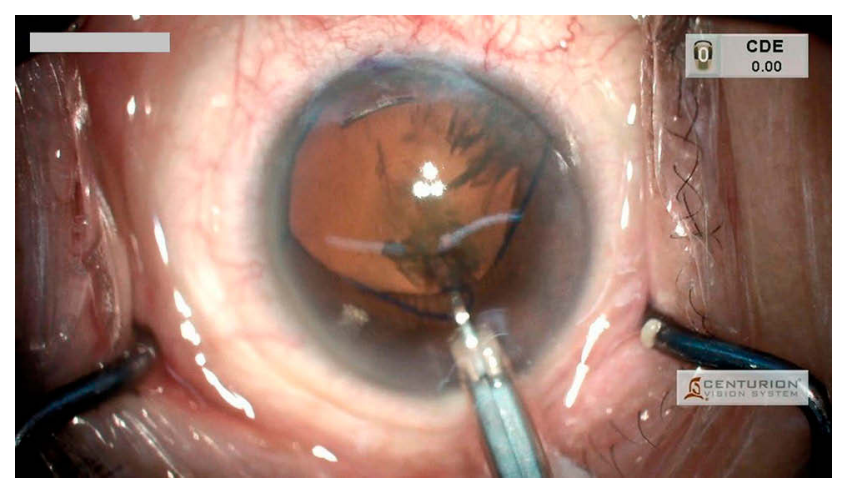

Figure 3 A Malyugin ring, a pupil-expanding device, was injected via the main incision. Cumulative dissipated energy (CDE) was set at 0.00 at the time the figure was captured. rotation. ${ }^{11,17-19}$ In comparison, the femtosecond laser-guided astigmatic correction could result in more stable and accurate long-term outcomes. To ensure the best results from the procedure, we decided to employ a double-docking technique and not perform all the laser cuts at once. This approach allowed us to avoid changing the shape of the patient's cornea from the injection of the viscoelastic device into the anterior chamber, which was necessary in this case for the Malyugin ring insertion. Such a shape change would inevitably lower the femtosecond laser's precision and docking location; therefore, the viscoelastic device was used only after the first docking, during which the FSAK was performed. The Z8 model has a liquid patient interface for cataract surgery, which prevents the cornea from changing shape through performing the double-docking technique. Even though inserting a toric IOL is a common method to correct high-degree astigmatism, ${ }^{20}$ it is inapplicable for patients with low-degree astigmatism. Toric IOLs with less than $1.25 \mathrm{D}$ power, not to mention the toric plus multifocal IOLs, are relatively new. Hence, further evaluation of their effectiveness and the associated complications is required. ${ }^{21}$ Traditionally, patients with low-degree astigmatism either receive manual limbal relaxing incisions or do not pursue treatment at all. However, with the doubledocking technique, the patient's astigmatism can be corrected using the femtosecond laser, and the benefits of all FLACS steps can be reaped.

The quality of the surgical outcomes and the safety of employing FLACS are improving through strengthened surgeon experiences and technological advances. Moreover, the femtosecond laser has provided the benefits of FLACS to the patients, such as using FSAK to correct astigmatism and increasing the circularity and reproducibility of the capsulotomy. ${ }^{22}$ However, some femtosecond lasers require their own surgical bed that needs to be placed in a separate room outside the operating area. The Femto LDV Z8 (Ziemer) allows enhanced apparatus mobility, and the device can be placed in the same room as the phacoemulsion system. For patients with small pupils, the decrease in overall surgical time reduces the release of inflammatory cytokines. ${ }^{14}$

Previous studies have reported an association between IFIS and the intake of $\alpha$-blockers (tamsulosin), which are commonly used for the treatment of benign prostatic hyperplasia and hypertension; the drugs are also risk factors for IFIS. $^{5}$

The Malyugin ring is the preferred pupil-expanding device for small pupils and is used instead of iris hooks in FLACS. Though the combination of the Malyugin ring and the iris hook ${ }^{5}$ with trimming of the iris hook ends ${ }^{14}$ 


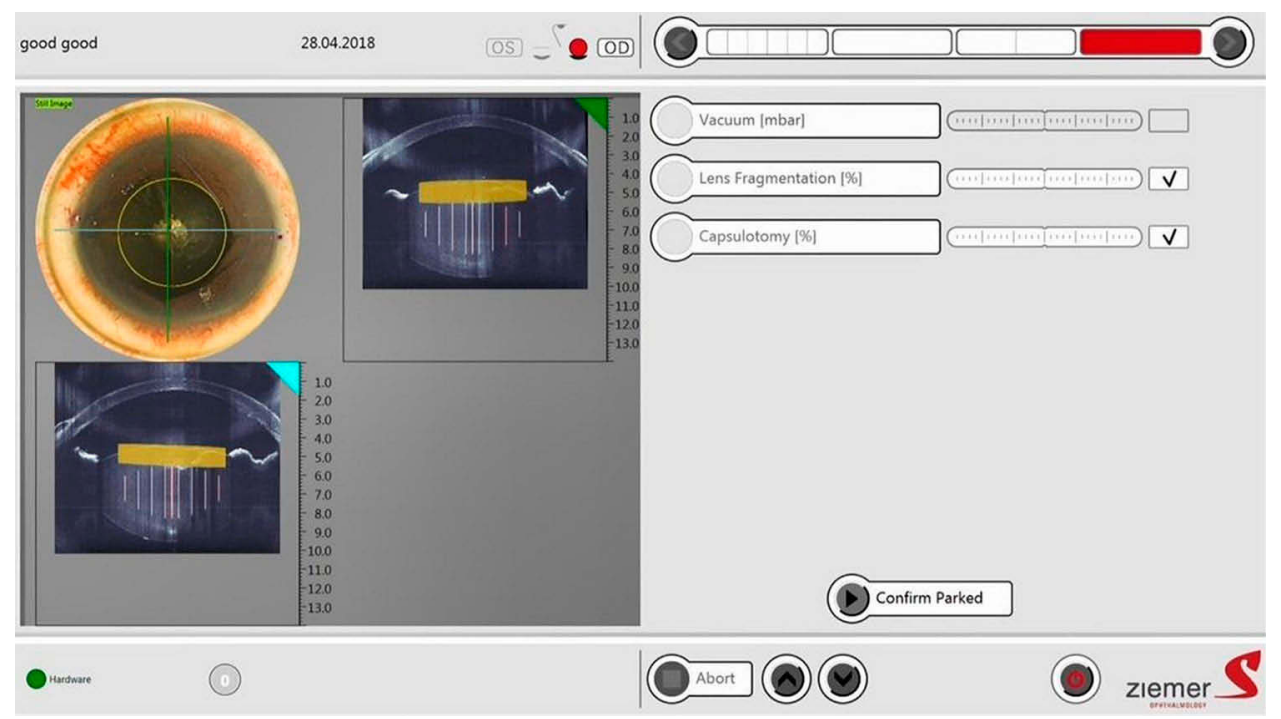

Figure 4 Second docking image from Z8.

before the docking can also be successful, the use of the Malyugin ring in complex cataract surgeries is the simpler and more effective method since it allows a faster initial visual recovery rate. ${ }^{23}$ The insertion of the Malyugin ring via the main incision does not necessitate any new incision. In comparison, the insertion of iris hooks often requires four or five extra incisions. Hence, the patient would require a longer recovery time for these incisions to heal. As the number of corneal incisions increases, the patient's surgically induced astigmatism could also be influenced, resulting in more post-operative complications.

In conclusion, the use of the mobile and compact Femto LDV Z8 (Ziemer) and Malyugin ring combined with the double-docking technique facilitated a successful cataract surgery in the IFIS patient with poorly dilated pupil. A powerful correction of low-degree astigmatism was achieved, and all benefits of the femtosecond laser were gained by avoiding changing the shape of the patient's cornea from the injection of viscoelastic device into the anterior chamber, which could lower the femtosecond laser's precision and docking location.

Table 2 Settings of the Second Docking Oculus Dextrus (O)D

\begin{tabular}{|l|l|l|l|l|}
\hline \multicolumn{2}{|l|}{ Second Docking } & CCC & & $\begin{array}{l}\text { Lens } \\
\text { Fragmentation }\end{array}$ \\
\hline OD & & & & \\
& & & & \\
& Center Method & Limbus & Center Method & Limbus \\
& Diameter (mm) & 5.7 & Diameter (mm) & 5.8 \\
& Laser Power (\%) \\
& Resection Height & 1 & Laser Power (\%) & 125 \\
& & Number of & 4 \\
& & Segments & \\
\hline
\end{tabular}

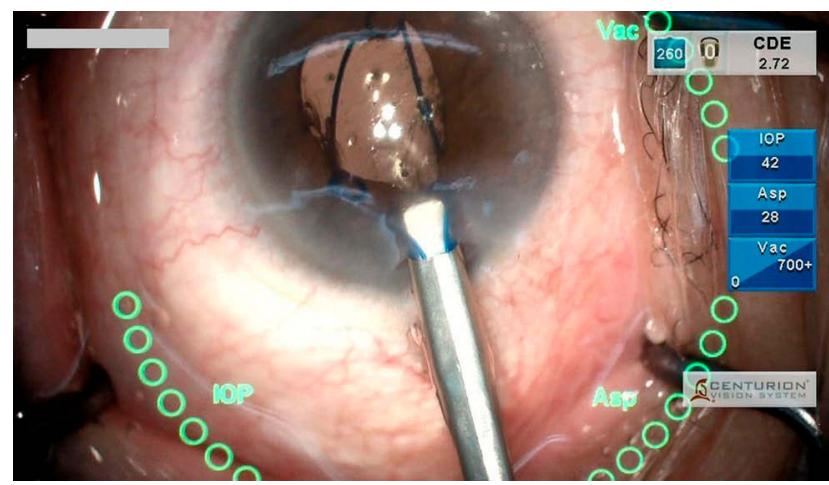

Figure 5 The trailing eyelet of the Malyugin ring was disengaged from the iris and the iris manipulator was used to hook onto the trailing eyelet and into the injector plate. When the interface was captured, cumulative dissipated energy (CDE) was set at 2.72, Intraocular pressure (IOP) at 42, aspiration (Asp) at 28 , and vacuum at $700+$.

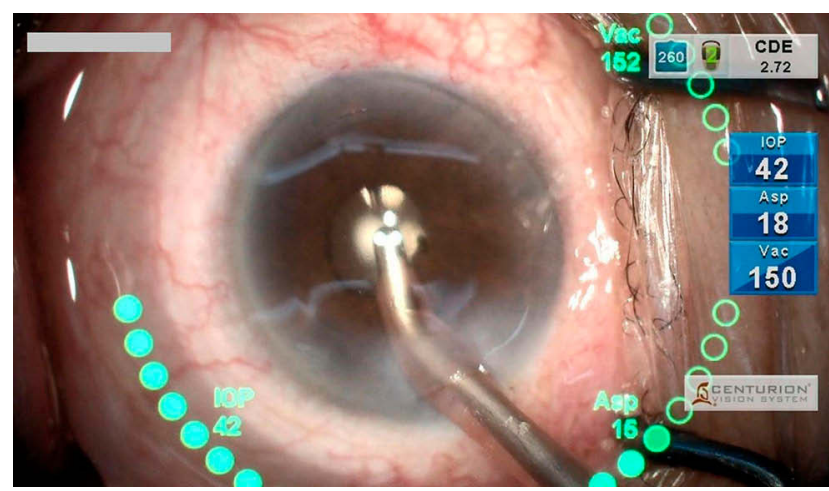

Figure 6 Removal of the viscoelastic device was done followed by irrigation and aspiration (Asp). When the interface was captured, cumulative dissipated energy (CDE) was set at 2.72 , Intraocular pressure (IOP) at 42, aspiration (Asp) at 18, and vacuum at 150 . 
Viscoelastic device was only used after the first docking when the FSAK was performed.

\section{Ethics and Consent Statement}

Written informed consent has been obtained from the patient to include case details and accompanying images. Institutional approval from the Institutional Review Board of Antai TianSheng Memorial Hospital was obtained (18-024-B).

\section{Funding}

This research did not receive any grants from funding agencies in the public, commercial, or not-for-profit sectors.

\section{Disclosure}

The authors have no conflicts of interest to declare.

\section{References}

1. Villegas EA, Alcon E, Artal P. Minimum amount of astigmatism that should be corrected. J Cataract Refract Surg. 2014;40(1):13-19. doi:10.1016/j.jcrs.2013.09.010

2. Wang L, Zhang S, Zhang Z, et al. Femtosecond laser penetrating corneal relaxing incisions combined with cataract surgery. $J$ Cataract Refract Surg. 2016;42(7):995-1002. doi:10.1016/j.jcrs.2016.04.020

3. Gonzalez Martin-Moro J, Munoz Negrete F, Lozano Escobar I, Fernandez Miguel Y. Intraoperative floppy-iris syndrome. Arch Soc Esp Oftalmol. 2013;88(2):64-76. doi:10.1016/j.oftal.2011.09.023

4. Chatziralli IP, Peponis V, Parikakis E, Maniatea A, Patsea E, Mitropoulos P. Risk factors for intraoperative floppy iris syndrome: a prospective study. Eye. 2016;30(8):1039-1044. doi:10.1038/ eye.2016.122

5. Malyugin B, Sobolev N, Arbisser LB, Anisimova N. Combined use of an iris hook and pupil expansion ring for femtosecond laser-assisted cataract surgery in patients with cataracts complicated by insufficient mydriasis and an ectopic pupil. J Cataract Refract Surg. 2016;42 (8):1112-1118. doi:10.1016/j.jcrs.2016.07.001

6. Malyugin B. Review of Surgical Management of Small Pupils in Cataract Surgery. Vol 9. 2011.

7. Conrad-Hengerer I, Hengerer FH, Schultz T, Dick HB. Femtosecond laser-assisted cataract surgery in eyes with a small pupil. $J$ Cataract Refract Surg. 2013;39(9):1314-1320. doi:10.1016/j.jcrs.2013.05.034

8. Malyugin B, Anisimova N, Antonova O, Arbisser LB. Simultaneous pupil expansion and displacement for femtosecond laser-assisted cataract surgery in patients with lens ectopia. J Cataract Refract Surg. 2018;44(3):262-265. doi:10.1016/j.jcrs.2018.01.014
9. Jirasková N, Rozsíval P, Lešták J. Use of malyugin pupil expansion ring in femtosecond laser-assisted cataract surgery. J Clin Exp Ophthalmol. 2013;4:2.

10. Day AC, Gore DM, Bunce C, Evans JR. Laser-assisted cataract surgery versus standard ultrasound phacoemulsification cataract surgery. Cochrane Database Syst Rev. 2016;7:Cd010735.

11. Nubile M, Carpineto P, Lanzini M, et al. Femtosecond laser arcuate keratotomy for the correction of high astigmatism after keratoplasty. Ophthalmology. 2009;116(6):1083-1092. doi:10.101 6/j.ophtha.2009.01.013

12. Mastropasqua L, Toto L, Mastropasqua A, et al. Femtosecond laser versus manual clear corneal incision in cataract surgery. $J$ Refract Surg. 2014;30(1):27-33. doi:10.3928/1081597X-20131217-03

13. Qian DW, Guo HK, Jin SL, Zhang HY, Li YC. Femtosecond laser capsulotomy versus manual capsulotomy: a Meta-analysis. Int J Ophthalmol. 2016;9(3):453-458. doi:10.18240/ijo.2016.03.23

14. Nanavaty MA, Bedi KK, Vasquez-Perez A. Small-pupil cataract surgery with/without hooks using femtosecond laser with fluid interface. Can J Ophthalmol. 2018;53(3):. doi:10.1016/j. jcjo.2017.08.020.

15. Baharozian CJ, Song C, Hatch KM, Talamo JH. A novel nomogram for the treatment of astigmatism with femtosecond-laser arcuate incisions at the time of cataract surgery. Clin Ophthalmol. 2017;11:1841-1848. doi:10.2147/OPTH.S141255

16. Hoffart L, Proust H, Matonti F, Conrath J, Ridings B. Correction of postkeratoplasty astigmatism by femtosecond laser compared with mechanized astigmatic keratotomy. Am J Ophthalmol. 2009;147 (5):779-787, 787.e771. doi:10.1016/j.ajo.2008.12.017

17. Chang DF. Comparative rotational stability of single-piece open-loop acrylic and plate-haptic silicone toric intraocular lenses. $J$ Cataract Refract Surg. 2008;34(11):1842-1847. doi:10.1016/j.jcrs.200 8.07.012

18. Kwartz J, Edwards K. Evaluation of the long-term rotational stability of single-piece, acrylic intraocular lenses. Br J Ophthalmol. 2010;94 (8):1003-1006. doi:10.1136/bjo.2009.163485

19. Aristeidou A, Taniguchi EV, Tsatsos M, et al. The evolution of corneal and refractive surgery with the femtosecond laser. Eye Vis. 2015;2:12. doi:10.1186/s40662-015-0022-6

20. Alio JL, Agdeppa MC, Pongo VC, El Kady B. Microincision cataract surgery with toric intraocular lens implantation for correcting moderate and high astigmatism: pilot study. $J$ Cataract Refract Surg. 2010;36(1):44-52. doi:10.1016/j.jcrs.2009.07.043

21. Levitz L, Reich J, Roberts K, Hodge C. Evaluation of toric intraocular lenses in patients with low degrees of astigmatism. Asia Pac $J$ Ophthalmol. 2015;4(5):245-249. doi:10.1097/APO.0000000 000000112

22. Nagy ZZ, Mastropasqua L, Knorz MC. The use of femtosecond lasers in cataract surgery: review of the published results with the LenSx system. J Refract Surg. 2014;30(11):730-740. doi:10.3928/ 1081597X-20141021-04

23. Hanna JKN, Khouri AS. Visual outcomes after uncomplicated complex cataract surgery: malyugin ring versus iris hooks. Invest Ophthalmol Vis Sci. 2014;55.
International Medical Case Reports Journal

\section{Publish your work in this journal}

The International Medical Case Reports Journal is an international, peer-reviewed open-access journal publishing original case reports from all medical specialties. Previously unpublished medical posters are also accepted relating to any area of clinical or preclinical science. Submissions should not normally exceed 2,000 words or 4 published pages including figures, diagrams and references. The manuscript management system is completely online and includes a very quick and fair peer-review system, which is all easy to use. Visit http://www.dovepress.com/testimonials.php to read real quotes from published authors. 